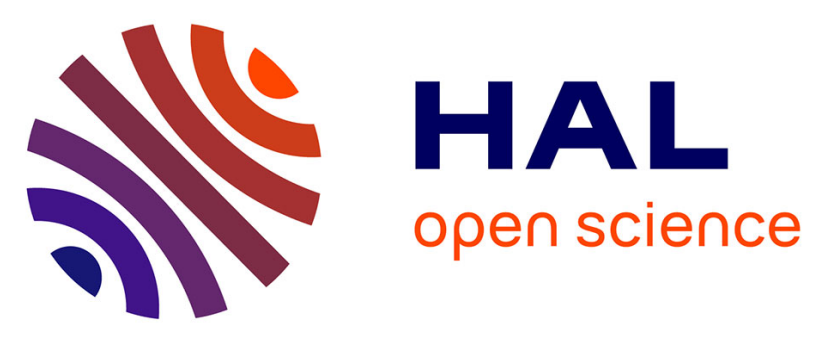

\title{
Multi-geophysical approach for the characterization of thermally-induced cracks in granite: discussion of reproducibility and persistence
}

\author{
Mohamed Salah Boussaid, Céline Mallet, Kévin Beck, Clara Jodry
}

\section{To cite this version:}

Mohamed Salah Boussaid, Céline Mallet, Kévin Beck, Clara Jodry. Multi-geophysical approach for the characterization of thermally-induced cracks in granite: discussion of reproducibility and persistence. Pure and Applied Geophysics, 2020, 177, pp.3301-3314. 10.1007/s00024-020-02438-8 . hal$02361662 \mathrm{v} 2$

\section{HAL Id: hal-02361662 \\ https://hal.science/hal-02361662v2}

Submitted on 12 Feb 2020

HAL is a multi-disciplinary open access archive for the deposit and dissemination of scientific research documents, whether they are published or not. The documents may come from teaching and research institutions in France or abroad, or from public or private research centers.
L'archive ouverte pluridisciplinaire HAL, est destinée au dépôt et à la diffusion de documents scientifiques de niveau recherche, publiés ou non, émanant des établissements d'enseignement et de recherche français ou étrangers, des laboratoires publics ou privés.

\section{(1) (1) $\$$}

Distributed under a Creative Commons Attribution - NonCommercial - NoDerivatives $\mid 4.0$ 


\title{
Multi-geophysical approach for the characterization of thermally-induced cracks in granite: discussion of reproducibility and persistence
}

\author{
Mohamed Salah Boussaid ${ }^{1}$, Céline Mallet ${ }^{1,2}$, Kévin Beck ${ }^{1}$, and Clara Jodry ${ }^{2}$ \\ ${ }^{1}$ Université d'Orléans, Université de Tours, INSA Centre Val de Loire - Laboratoire de Mécanique Gabriel Lamé - Polytech Orléans, 8 rue Léonard de Vinci, \\ 45072 Orléans, France \\ ${ }^{2}$ Univ. Orléans, CNRS, BRGM, ISTO, UMR 7327, F-45071, Orléans, France
}

\begin{abstract}
We study damage induced by low temperature variations in granite samples given their role in shallow geological reservoirs. We consider two thermal treatments, slow cooling and thermal shock, and implement a multi-geophysical approach to characterize the induced micro-scale damage. The methodology consists in monitoring elastic wave velocity and thermal conductivity as well as describing the damage by the way of Hg-porosity measurements and microscopic observations. To discuss the reproducibility of the induced damage, the same thermal protocol is performed on five samples. Our first results indicate that the thermal shock leads to a more pronounced damage. This is interpreted to be due to a larger variety of nucleated intragranular and intergranular cracks as observed by SEM and optic microscope. Yet, this more significant damage does not appear reproducible from one sample to another compared to the damage introduced by slow cooling. According to this first result, thereby, we propose a timely monitoring of elastic wave velocity, conductivity and Hg-porosity. It appears that the damage introduced by the slow cooling, unlike the thermal shock, does not present a long persistence. Indeed, after 15 days, the different properties had returned to their initial state. A time-dependence mechanism is proposed to discuss this observed process.
\end{abstract}

\author{
Keywords \\ cracks \\ thermal treatment \\ granite \\ elastic wave velocity \\ microscopic observations \\ thermal conductivity \\ porosity
}

\section{Introduction}

Thermally-induced cracks in rocks are encountered in various fields due to various natural or anthropic heating and cooling processes occurring at different rates and degrees [Ringwood, 1985; Cappa and Rutqvist, 2011; Feng et al., 2012; Nakaten et al., 2014]. It is especially true when considering engineering and geological applications such as geothermal reservoirs, radioactive waste storage and oil field development. The characterization and prediction of the crack network evolution under thermal variations is therefore of major interest [Kranz, 1983]. It is especially true in Enhanced Geothermal Systems, which consist of extending an existing cracked zone to improve the local permeability and transport of hot fluids. Many of such systems are find in granite formations such as the French site of Soultz-sous-Forêt [Rummel, 1992]. Hence, many studies emphasize the influence of thermally induced cracks on granite and on its physical or mechanical properties. For example, cracking changes elastic wave velocities [Lin, 2002; Nasseri et al., 2007; Chaki et al., 2008; Griffiths et al., 2017; Zhang et al., 2018]. Indeed, it has been observed that the two parameters, temperature and elastic wave velocity, are inversely correlated and induced microstructural damage affects all elastic properties [Hadley, 1976]. Other studies regarding granite subjected to thermal stresses focus on the variation of physical properties, particularly the porosity [David et al., 1999; Chen et al., 2017] and/or thermal properties such as thermal conductivity [Dwivedi et al., 2008; Kant et al., 2017; Zhao et al., 2018]. Those showed that the thermal conductivity of a cracked granite tends to decrease as temperature increases and thermally induced cracking occurs.

At the laboratory scale, there are different protocols used to thermally nucleate cracks. They differ by varying heating and cooling rates, maximal temperature and the number of cycles. It has been shown that cooling rate and maximal temperature are often key parameters in controlling the crack network [Belayachi et al., 2019]. In our study, two cooling protocols were considered: slow cooling [Wang et al., 2013] and thermal shocks [Kim et al., 2014; Mallet et al., 2015; Kumari et al., 2017; Jin et al., 2019], both presenting different maximal temperature [Beck et al., 2016]. Concerning the temperature range, it is common to find in the literature studies investigating the thermally induced cracks from $200^{\circ} \mathrm{C}$ to $600^{\circ} \mathrm{C}$ [Zhao et al., 2017; Rong et al., 2018; Gautam et al., 2018]. However, in the field, thermal ranges are not always that high, especially in shallow reservoirs. Consequently, it is of great interest to study the range of $100-200^{\circ} \mathrm{C}$ for conventional geothermal projects [Rummel, 1992], especially since micro-cracks may still occurs at these temperatures. Indeed, it has been shown that cracks may start to nucleate at temperature of $75^{\circ} \mathrm{C}$ [Richter and Simmons, 1974]. Our study aims to investigate the thermally induced cracks in granite, at these low temperatures, through a multi-geophysical characterization [Zhao et al., 2017] of their density, connectivity and time-persistence.

Crack density will be described through elastic wave velocity measurements (see the recent review of Guéguen and Kachanov [2011]). The connectivity of the crack network will be discussed through thermal conductivity [Xiong and Liew, 
2016; Wuttke et al., 2017] and mercury porosity measurements. Lastly, the crack geometry will be illustrated by Scanning Electron Microscopy (SEM) pictures.

This paper aims at answering three issues in the context of cracked-enhanced geothermal reservoir in granite. First, describe the thermally induced crack network in granite submitted to low temperatures variations and compare the effect of slow and instantaneous cooling. Then, and from a more general point of view, we discuss the reproducible and persistence aspects of such thermally-induced crack networks. Indeed, many researchers carry out thermal treatments considering as a consensus that the reproducibility is validated. We would like to verify this last point by answering two questions: is the result of these treatments the same from one sample to another? And is it persistent after few days?

\section{Methodology and theoretical context}

\subsection{Samples}

The samples used in this study were grey fine-grained granite that presented an average grain size of 200-300 $\mu \mathrm{m}$ with an initial porosity of 1.4\%, determined with $\mathrm{Hg}$-porosity (presented below). The initial P-wave velocity was about $4070 \mathrm{~m} / \mathrm{s}$. These values may seem low but they are quite consistent with an initially damaged granite containing micro-cracks that is often described with $\mathrm{V}_{P}$ around 4000-4500 m/s [Lin, 2002]. The initial thermal conductivity has been found to be $2,35 \mathrm{~W} / \mathrm{m} . \mathrm{K} \pm 0.09$. Its modal composition was obtained with XRD. Because its location of provenance is unknown, we named it grey granite and, in order to implant it in the literature, we compared it to some well-studied granite: Westerly granite and La Peyratte granite (Table 1 and Figure 1).

Table 1 Grey granite compared to La Peyratte and Westerly granites.

\begin{tabular}{llll}
\hline & Grey granite & La Peyratte & Westerly \\
\hline Composition & 40\% quartz, & 28,5\% quartz, & 27\% quartz, \\
& 13\% feldspar & $20 \%$ feldspar & $36 \%$ feldspar \\
& 14\% plagioclase, & 38,5\% plagioclase, & $30 \%$ plagioclase, \\
& $24 \%$ biotite, & $8 \%$ biotite, & $6 \%$ biotite, \\
Grain size & $9 \%$ muscovite & $5 \%$ muscovite & $1 \%$ accessories \\
Porosity & $200-300 \mu \mathrm{m}$ & $200 \mu \mathrm{m}$ & $500 \mu \mathrm{m}$ \\
Reference & this study & [Wang et al., 2013] & [Spray, 2010; Wang et al., 2012] \\
\hline
\end{tabular}
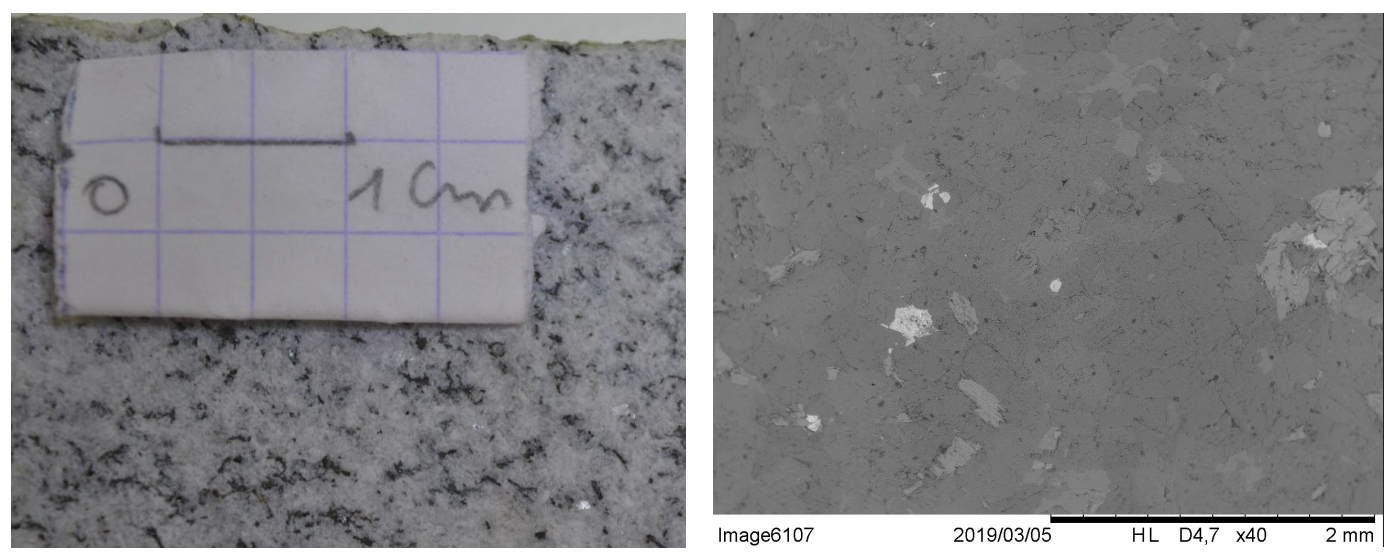

Figure 1 Photography and microscopic view by Scanning Electron Microscopy (x40) of the granite used in this study.

A total of 27 prismatic samples of $3 \times 3 \times 6 \mathrm{~cm}$, were cut with an accuracy of $1 \mathrm{~mm}$ checked with a calipers. They are summarized in Table 2.

\subsection{Thermal treatments}

The samples were submitted to two different thermal treatments (Figure 2). They differed by their cooling path. For both treatments, the used oven had a maximal temperature of $200^{\circ} \mathrm{C}$ with an accuracy of $0.1^{\circ} \mathrm{C}$. This oven was regulated to program automatic cycles. The temperature paths were as follow: temperature was increased up to a maximal temperature at a rate of $1^{\circ} \mathrm{C} / \mathrm{min}$ in order to avoid any dynamic damage during the heating [Ougier-Simonin et al., 2011; Mallet et al., 2013; Siratovich et al., 2015]. Samples were maintained at this level during at least $6 \mathrm{~h}$ to ensure a complete temperature diffusion within the sample core (recently discussed by Zhang et al. [2018]). Then, for the first thermal treatment, samples 


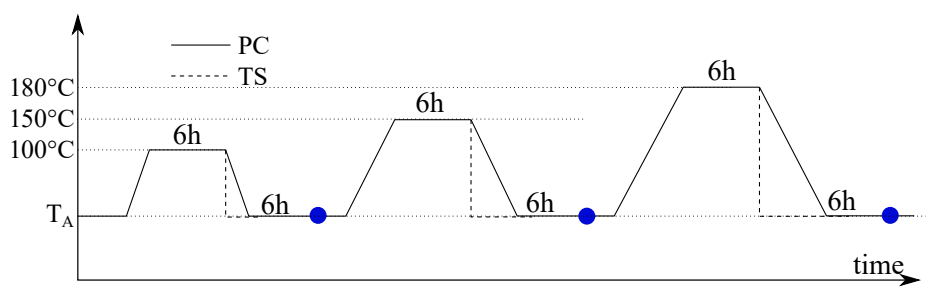

Figure 2 The two considered thermal treatments. PC stands for Progressive Cooling and TS for Thermal Shocks. Blue dots represent the measurements performed after $6 \mathrm{~h}$ of cooling.

Table 2 Samples, thermal treatments and measured properties. PC and TS stand for Progressive cooling and Thermal Shock, respectively.

\begin{tabular}{lll}
\hline Samples & Thermal treatment & Measurements \\
\hline 1 to 5 & PC & $\mathrm{V}_{P}$, thermal conductivity, $\mathrm{V}_{P}$ at day 15 \\
6 to 10 & TS & $\mathrm{V}_{P}$, thermal conductivity, $\mathrm{V}_{P}$ at day 15 \\
11 to 12 & PC & $\mathrm{V}_{P}$ and thermal conductivity during 12 days \\
13 to 27 & PC & Porosity at initial state and during 12 days (smaller samples) \\
\hline
\end{tabular}

were cooled down at $1^{\circ} \mathrm{C} / \mathrm{min}$. This treatment is referred as progressive cooling in the paper. For the second treatment, samples were quenched in a few second into water at ambient temperature. This treatment is referred as thermal shock.

Three maximal temperatures were investigated: $100^{\circ} \mathrm{C}, 150^{\circ} \mathrm{C}$ and $180^{\circ} \mathrm{C}$ as presented in Figure 2 . Between treatments, during the cooling and after, samples were kept at $20^{\circ} \mathrm{C}$ in a dry environment.

\subsection{Physical measurements}

Physical properties were measured after $6 \mathrm{~h}$ of cooling. Table 2 presents the 27 samples with corresponding thermal treatments and measurements.

\subsubsection{Elastic wave velocity and crack density}

Elastic wave velocities were measured with piezoelectric sensors (PI Ceramic), sensitive to P-waves, put directly on the sample surface (Figure 3a). Honey was used as a coupling gel to avoid attenuation due to an imperfect contact between the sample and the sensor [Ndao et al., 2017]. Between successive measurements, the couplant was always removed and the sample cleaned.

The principle of the experiment was as follow: an electric pulse of $150 \mathrm{~V}$ was generated and transmitted to the first sensor. It triggered a mechanical vibration that propagated into the sample. The opposite sensor recorded this vibration and transformed it into an electrical signal that was amplified at $30 \mathrm{~dB}$. A dedicated interface allowed the observation of the recorded waveform. Finally, the travel time was manually picked. The elastic wave velocity was deduced knowing the distance between the two sensors [Birch, 1960]. Considering the potential error on the manual picking, the sampling rate and the accuracy of the face parallelism, wave velocities were determined with an accuracy of $\pm 50 \mathrm{~m} / \mathrm{s}$.

Elastic wave velocity decrease will be interpreted in terms of increasing crack density. This mechanical parameter introduced by [Walsh, 1965] is commonly considered in cracking studies. The link between velocity decrease and crack density increase has been proved through the effective medium theory (see the work of Kachanov [1980] and the recent review of Guéguen and Kachanov [2011]). Unfortunately, we do not have the necessary S-wave sensors. Thus, in this study crack density will not be quantitatively described but still, the P-wave decrease will, from a qualitative point of view, be interpreted in terms of crack density increase.

\subsubsection{Thermal conductivity and crack connectivity}

Our thermal conductivity measurements were performed by the hotwire technique (Figure 3b) following ASTM D593097 and the RILEM recommendations (AAC11-3). The Neotim apparatus was equipped with a probe of 50 mm-length. This probe was very thin and placed between two samples of the studied material with symmetric assembly. Then, the principle was as follow: an electric power of $2 \mathrm{~W}$ was applied on the wire during $1 \mathrm{~min}$ and produced by Joule heating, a weak warm-up of the material (a few degree above ambient temperature). The rise of temperature on the material was measured by a thermocouple in contact with the two samples. This thermocouple was one millimeter away from the hot wire. The hotwire technique was based on a transient method, and the thermal conductivity was connected inversely proportional to the rise in temperature during 1 min after the beginning of heating.

The measurement range of thermal conductivity is $0.02-5 \mathrm{~W} / \mathrm{mK}$ with an accuracy of $\pm 5 \%$. In order to improve the accuracy, the average conductivity was measured 10 times on the same couple of samples for every treatment.

Note that, this measurement was actually an effective thermal conductivity. Indeed our sample can be locally considered 

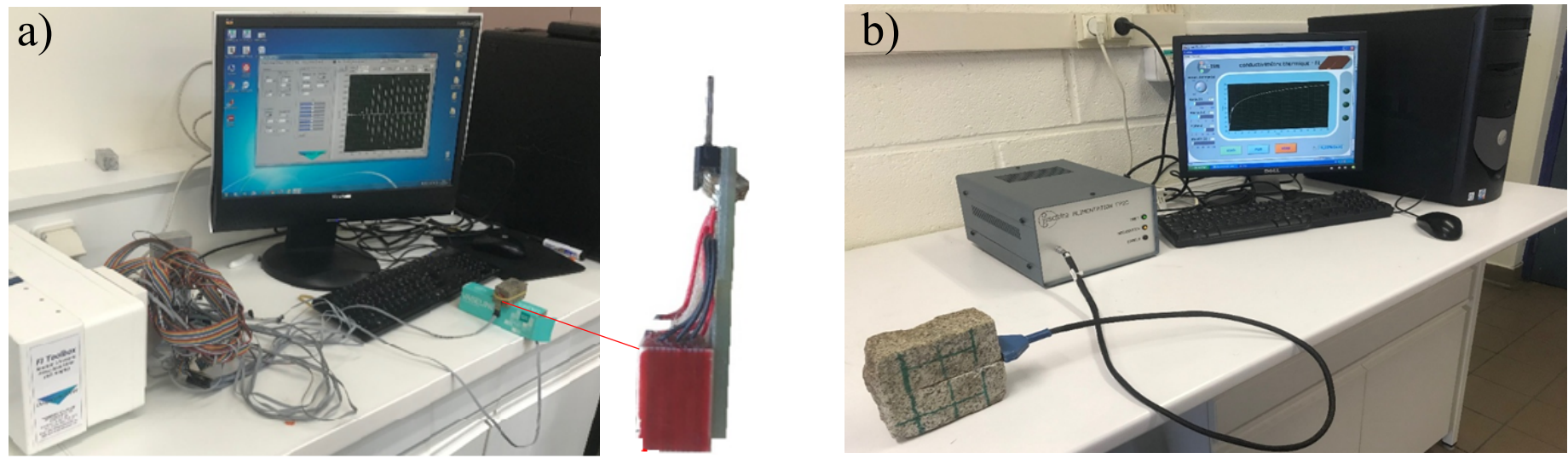

Figure 3 Pictures of our sensors for geophysical analyses: a) Piezoelectric sensor and its device. b) Thermal conductivity set-up.

as heterogeneous. However, for sake of simplicity, and because grains were small and homogeneous (at the sample scale) in our granite, we keep the term of thermal conductivity in the full paper.

As shown by Storz et al. [2000], Jones et al. [2012] and Xiong and Liew [2016], thermal and electrical conductivities are sensitive to crack connectivity (for similar crack densities). Indeed, an increasing permeability at constant porosity increases crack connectivity, which leads to an electrical conductivity [Kemna et al. , 2002; Han et al. , 2015] or thermal conductivity [Xiong and Liew, 2016] decrease.

In our study, we won't focused on inversion procedure that is a full subject of investigation (see the recent review of Carcione et al. [2007] for the couple inversion procedures of seismic and conductivity data), but describe the relative evolution of the crack connectivity.

\subsubsection{Porosity measurement}

Porosity measurements were performed using a mercury porosimeter. The apparatus was an Autopore IV 9500 porosimeter from Micromeritics (pressure used was from 0.003 MPa to $400 \mathrm{MPa}$ ). Measurements were performed on smaller cylindrical samples of $1 \mathrm{~cm}$-diameter and $2 \mathrm{~cm}$-length. These samples were not sub-samples of the thermally treated prismatic samples but were cut on purpose, then thermally treated before measuring the porosity. one could wondered if the comparison of the results is possible due to size effects. However, to answer and discuss this point much more different sizes would be needed with a full comparison of each properties (seismic, electric and porosity). This was not possible with our materials since velocity and thermal conductivity sensors are too large to made measurement on these small samples. Thus, we don't discuss the size effects and consider that it is comparable from the point of view of the global tendency.

\section{Results}

\subsection{Thermally-induced damages}

\subsubsection{Elastic wave velocity}

After each thermal treatment, the P-wave velocity was measured at room temperature (Figure 4) to monitor the evolution of the damage induced in the samples. The ten first samples were used: Samples 1 to 5 for the progressive cooling and samples 6 to 10 for the thermal shock (see Table 2).

The progressive cooling treatment gives a global decrease of P-wave velocity until $150^{\circ} \mathrm{C}$ followed by a slight increase of $50 \mathrm{~m} / \mathrm{s}$ at $180^{\circ} \mathrm{C}$. Despite this re-increase, we find that, between the initial and final state, the induced damage of the sample generate an average velocity decrease of $275 \mathrm{~m} / \mathrm{s}$. We note that each samples follow the same pattern with a discrepancy of $\pm 100 \mathrm{~m} / \mathrm{s}$ that stays constant from $100^{\circ} \mathrm{C}$ when damage increases.

For the thermal shock treatment, a global velocity decrease is observed throughout the experiment without any local re-increase around $150^{\circ} \mathrm{C}$ (except for one sample). Between the initial and the final states, the damage of the sample is characterized by an average velocity decrease of $575 \mathrm{~m} / \mathrm{s}$. However, this damage presents a larger discrepancy between the five samples with differences up to $\pm 350 \mathrm{~m} / \mathrm{s}$.

\subsubsection{Thermal conductivity}

The thermal conductivity was also measured at room temperature after each experiment (Figure 5) to monitor the progression of the damage manifested at the surface of the samples. The same ten first samples were used, 5 for both treatments (see Table 2).

For the progressive cooling, the thermal conductivity behavior is similar of the P-wave velocity behavior. There is a first decrease highlighting a sample's damage from 2.35 to $1.98 \mathrm{~W} / \mathrm{m} . \mathrm{K}$. Then, a rebound of $0.2 \mathrm{~W} / \mathrm{m} . \mathrm{K}$ around $150^{\circ} \mathrm{C}$, followed by a final decrease. This rebound is debatable in respect to the discrepancy of the results. Even then, the global decrease is interrupted.

For the thermal shock, the global decrease in thermal conductivity is continuous, as the P-wave velocity, and reaches a lower value of $1.8 \mathrm{~W} / \mathrm{m} . \mathrm{K}$ at $180^{\circ} \mathrm{C}$. We note that at the extreme values, corresponding to the highest damage level, the 

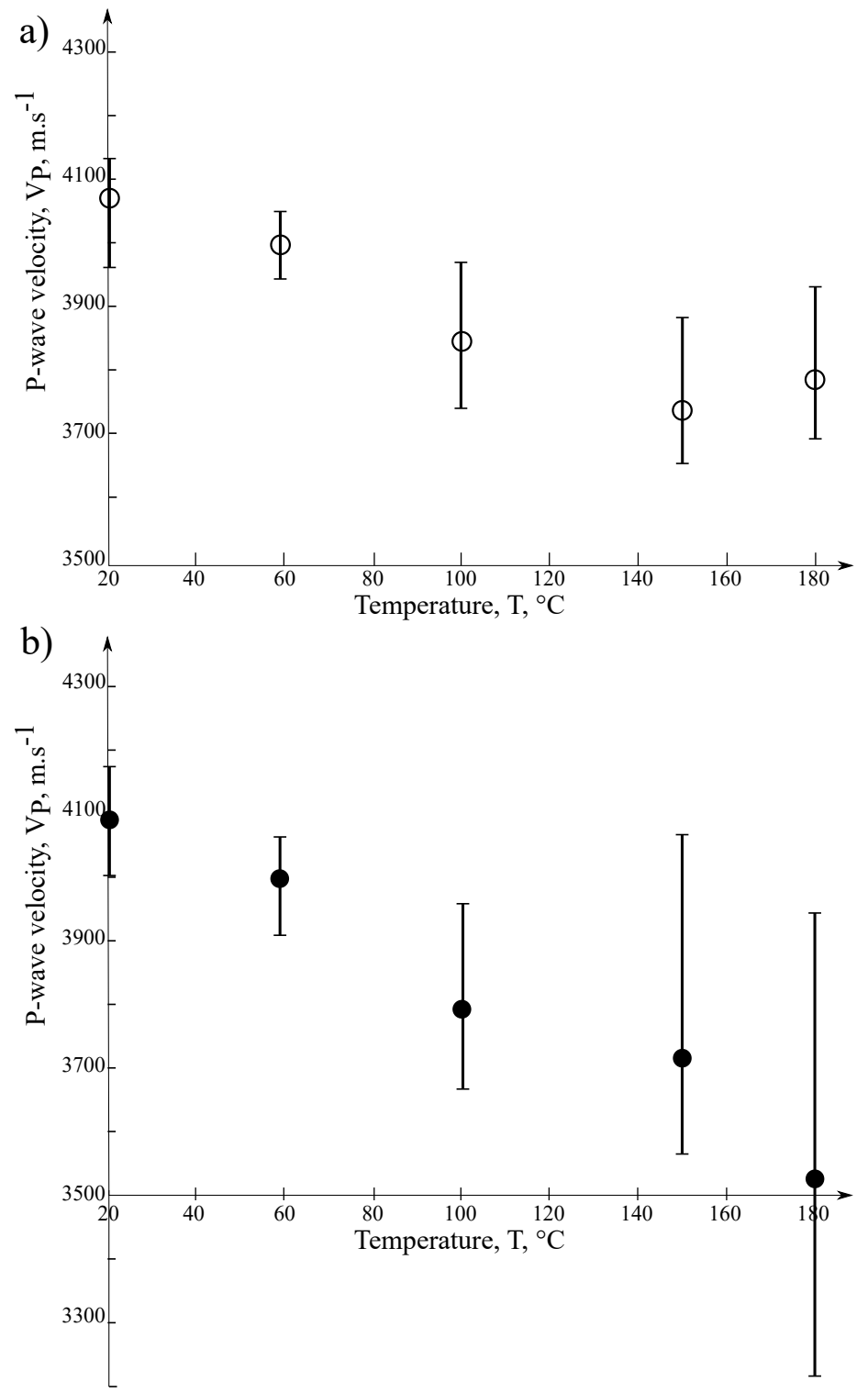

Figure 4 P-wave velocities measured after the thermal treatments for the progressive cooling (a) and the thermal shock (b). The different samples are represented without particular differentiation but the obtained dispersion is represented with vertical bars. The dots (empty for the progressive cooling and plain for the thermal shock) are the average values obtained for each temperature. 

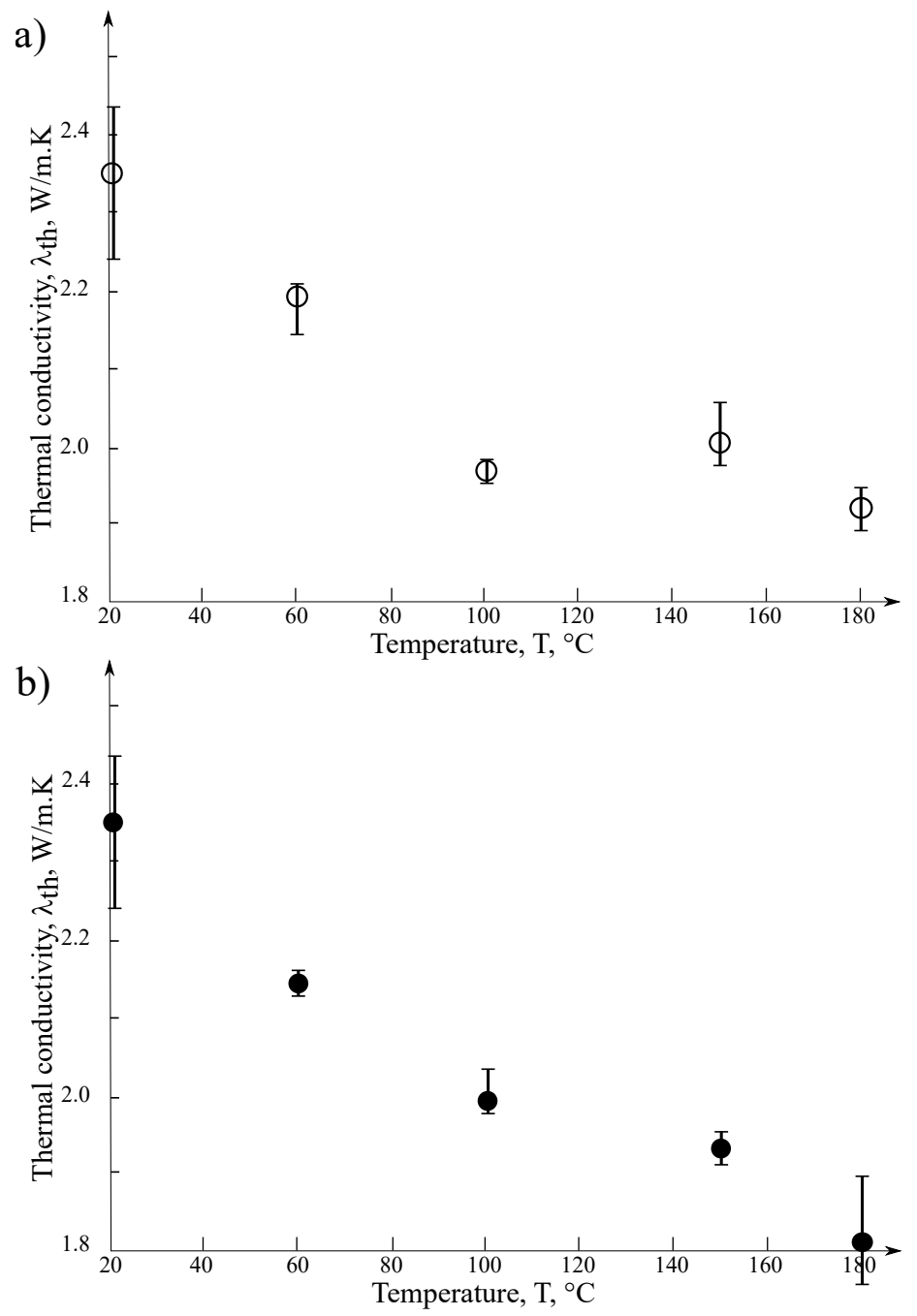

Figure 5 Thermal conductivity measured after the thermal treatments for the progressive cooling (a) and the thermal shock (b). The main value is represented with dots (empty for the progressive cooling and plain for the thermal shock) and the obtained discrepancy between the different samples is plotted as vertical bars. 


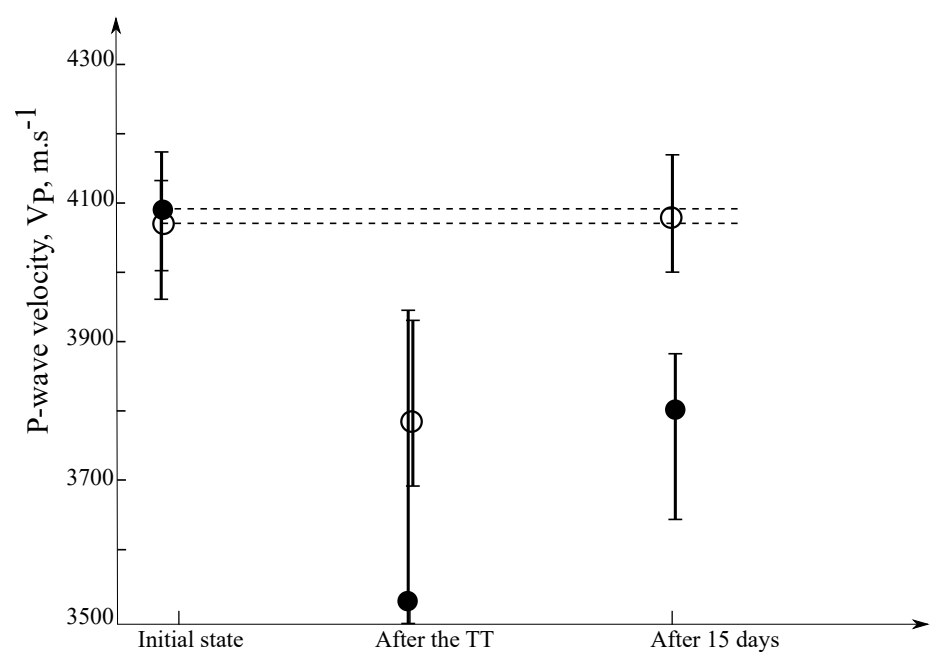

Figure 6 P-wave velocities at initial state, measured after the thermal treatments for the progressive cooling (empty circles) and the thermal shock (plain circles), and after 15 days. Dashed lines represent the initial state for both group of 5 samples.

discrepancy of the result is less accurate.

\subsection{Damage persistence}

Elastic wave velocities were re-measured on the first 10 samples, after 15 days and compared to the values obtained just after the thermal treatments (Figure 6). It appears that the damage induced by the progressive cooling to $180^{\circ} \mathrm{C}$ returns to its original value after 15 days. The damage induced by the thermal shock slightly reduces but remains non-negligible.

Since it is counter-intuitive for the damage to resorb after the progressive cooling treatment, further investigation were performed. Thus, P-wave velocity, thermal conductivity and Hg-porosity were measured on new samples (see Table 2) from 2 to 15 days after the progressive cooling protocol.

Time variation of the physical properties are presented in Figure 7. Points at day 0 represent the initial state while points at day 1 represent the properties measured just after the thermal treatment (corresponding to the first experiment).

The P-wave velocity starts to decrease, remains the same for 5 days before starting to slowly increase back to its initial state after 11 days.

The thermal conductivity has a similar trend although slower. This measure reduces and is almost constant up to 7 days then rises and, after 15 days, $87 \%$ of the initial state is recovered.

The measurement of the porosity presents an anomaly at day 2 that we unfortunately cannot really explain. Our hypothesis is that the two samples presented a singularity which/that we missed, however there is no possibility to verify it since they are now covered in mercury. Since this point is not in a good correlation with the following data and that our interpretations is based on global tendency, we choose to not take into account this particular value.

Without it, The global porosity behavior presents a correlated evolution to the P-wave velocity and thermal conductivity at an intermediate rate. First, with an increase of porosity of $0.6 \%$ (from 1.4 to $2 \%$ ). Then, the damage introduced by the progressive cooling remains constant during 5 days like the P-wave velocity and the thermal conductivity and then started to decrease yet slower than the P-wave velocity. As for the thermal conductivity, after 15 days, the initial state is not recovered.

\section{Discussion}

\subsection{Thermally induced damage linked to the literature}

A lot of studies [Richter and Simmons, 1974; Yong and Wang , 1980; Griffiths et al. , 2018] demonstrated, with acoustic emissions or seismic measurements, that crack nucleation and pre-existing crack propagation may start around $75^{\circ} \mathrm{C}$ in Granite. Lin [2002] also observed through strain measurements that thermal microcracking begins at a higher threshold of $100^{\circ} \mathrm{C}$. Our elastic wave velocity data shows (considering the discrepancy and error bar of $\pm 50 \mathrm{~m} / \mathrm{s}$ ) no damages at $60^{\circ} \mathrm{C}$ but that it starts at $100^{\circ} \mathrm{C}$, for both thermal treatments, as for Lin [2002]. While thermal conductivity seems to indicate that damage begins at $60^{\circ} \mathrm{C}$. However, we have to keep in mind that the induced damage seen by the thermal conductivity is not 3D since it comprises only surface data.

Looking at the global velocity behavior, the observed slowness induced by the thermal treatments has been noticed in the literature at similar temperatures (see Table 3). Jin et al. [2019] obtained a decrease of $3 \%$ at $100^{\circ} \mathrm{C}$ and $10 \%$ at $200^{\circ} \mathrm{C}$ and the same order of magnitude is found in other studies also carrying out slow cooling treatments [Johnson et al. , 1978; David et al., 1999; Chaki et al., 2008]. All previous results are consistent and give a positive correlation between temperature increase and thermally induced damage. Behaviors and order of magnitude obtained in our study are in agreement with previous studies (Table 3) despite the difference of the maximum temperatures targeted for these other studies. In that respect, it gives a positive correlation between temperature increase and thermally induced damage. In addition, for La Peyratte Granite Glover et al. [1995] observed a porosity variation up to $0.5 \%$ at similar temperatures 


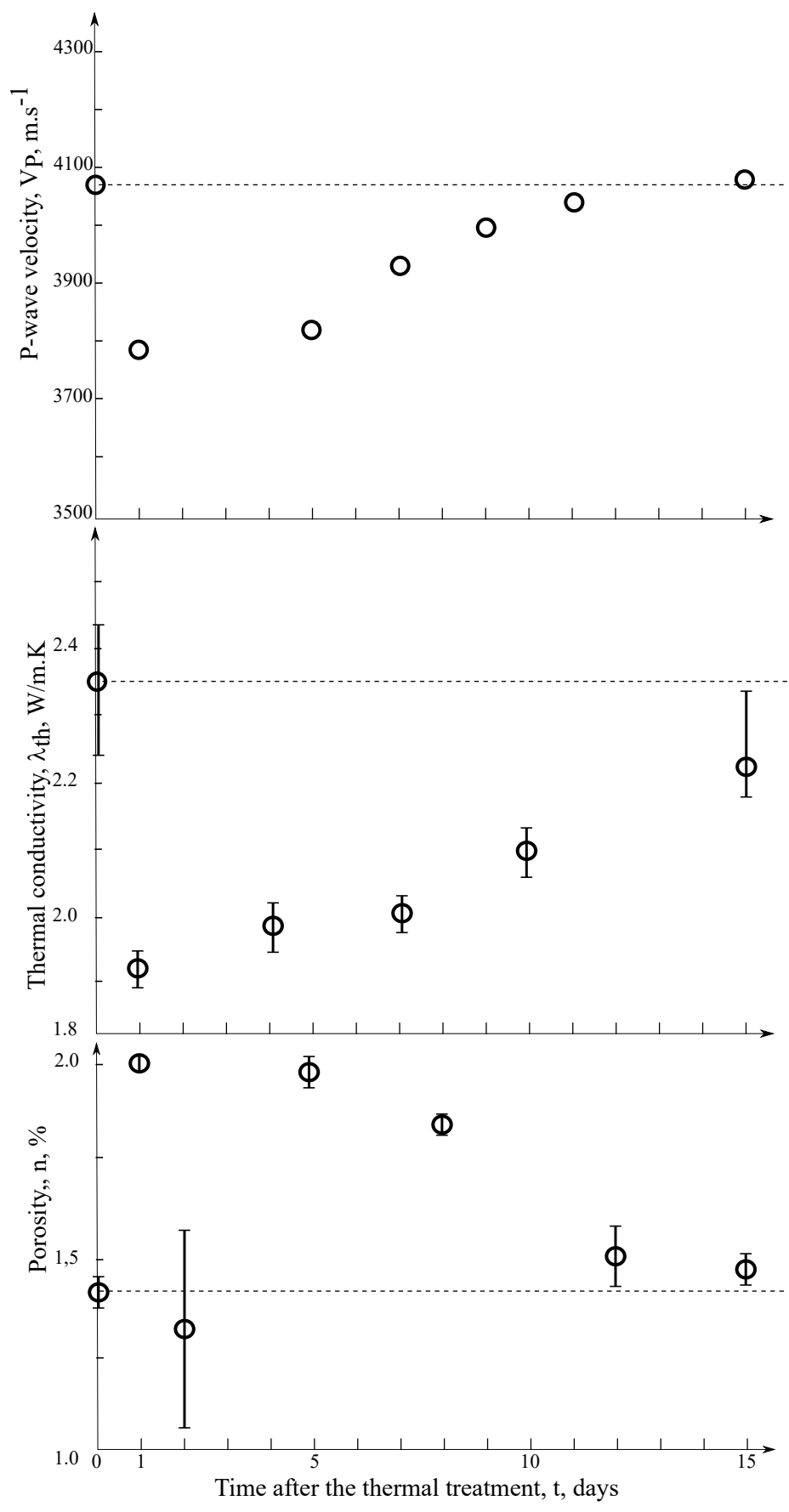

Figure 7 P-wave velocities, thermal conductivity and porosity at the initial state (day 0), after the thermal treatment of progressive cooling (day 1) and during 15 days. Initial state are highlighted with dashed lines. 
linked to an acoustic emission activity (from $100^{\circ} \mathrm{C}$ ) highlighting crack nucleation, and so velocity variation. In Westerly granite, Fredrich and Wong [1986] noted an increase in density from 4 to 4.5 of the amount of crack per unit length between initial state and $200^{\circ}$. These porosity and crack densities variations are also in good agreement with our results where a porosity variation of $0.6 \%$ is measured.

Table 3 Estimated elastic wave velocity variation after a progressive cooling at $180^{\circ} \mathrm{C}$.

\begin{tabular}{llll}
\hline Granite & Initial $\mathrm{V}_{P}(\mathrm{~m} / \mathrm{s})$ & Velocity decrease (\%) & Reference \\
\hline Grey Granite & 4070 & 7 & This study \\
Westerly Granite & 5000 & 4 & [Chaki et al., 2008] \\
Westerly Granite & 4400 & 16 & [Bauer et al., 1979] \\
La Peyratte Granite & 5500 & 9 & [David et al., 1999] \\
Indian Granite & 4300 & 9 & [Lin, 2002] \\
Shandong Granite & 4150 & 11 & [Jin et al., 2019] \\
Hubei Granite & 4300 & 15 & [Zhang et al., 2018] \\
\hline
\end{tabular}

\subsection{Progressive cooling versus thermal shocks}

Comparing both treatments , it appears that despite the low involved temperatures, a significant damage is induced into the samples, especially with thermal shock. As a matter of fact, a global velocity slowness of 575 versus $275 \mathrm{~m} / \mathrm{s}$ is reached between initial state and final temperature at $180^{\circ} \mathrm{C}$ for the thermal shock and the progressive cooling, respectively.

From literature, we know that there are two crack nucleation processes. On the one hand, cracks may be induced with homogeneous and gradual temperature changes. It causes a favored expansion of some minerals over others due to the difference in associated thermal expansion coefficients [Friedman et al., 1978; Bauer et al., 1979; Glover et al. , 1995]. On the other hand, cracks may be initiated due to a sudden change in temperature leading to very high local stresses [Jansen et al., 1993]. According to Siratovich et al. [2015] huge microstructural damage can then be observed inside and around grains with the development of defined cracks. These different behaviors could explain the differences observed between our two protocols. This has been also experienced by Jin et al. [2019] where they concluded that stresses from thermal shock have a greater effect on the rock than those from progressive cooling. Looking at our results, this previous observation is confirmed with thermal shock leading to much more significant damages of the sample. This result is quite intuitive when thinking of the brutality of the involved stresses [Ougier-Simonin et al., 2011].

Note however that opposite trend has been observed for various sandstones [Belayachi et al., 2019] highlighting the importance of the mineral composition and initial porosity, together with the difference between interlocking grains in granite and cemented grains in sandstone.

Microstructural observations , by optical microscope and SEM are presented in Figure 8. In samples submitted to thermal shock, we observe large cracks developed close to the sample's surface (Figure 8b), combined with cracks developing around (Figure 8c-d) and inside grains (Figure 8e-f) whereas in samples submitted to thermal shock but not in the one submitted to progressive cooling, only diffuse cracks are detected (Figure 8g-h). The two types of cracks observed in the shocked samples are referred as intergranular (Figure 8c-d) and intragranular (Figure 8e-f) cracks in literature [Nasseri et al., 2009] and can be found at higher temperatures in similar materials [Siratovich et al., 2015]. These observations confirm the interpretation made above of a larger crack variety induced by the thermal shocks and leading to a more important global damage.

A singularity is observed in measurements pertaining to induced damage by the progressive cooling . Indeed, the global velocity decrease observed in our granite after the $180^{\circ}$ treatment is comparable to similar studies performed on La Peyratte Granite [Glover et al. , 1995] or Westerly granite [Fredrich and Wong , 1986] as discussed above. However we obtain a velocity and thermal conductivity re-increase around $150^{\circ} \mathrm{C}$ that neither observed with the thermal shock, nor documented in literature due to the focus on higher temperatures.

We interpret this singularity to result from two competing microstructural behaviors. Similar singularities can be found in literature also interpreted in terms of dual behavior's competition [Darot et al., 1992]. In this study, the authors observed a permeability decrease associated to damage around temperatures of $150^{\circ} \mathrm{C}$. They interpreted it as low mineral expansion that caused thermally induced microcracks and permeability increase. But this expansion would have been so low that joins dilatation would have compensated the crack development, leading to a channel closure.

In our case, a similar dual competition can be described. First, around the range of $150^{\circ} \mathrm{C}$ a mineral dilatation is expected under thermal treatment [Cooper and Simmons, 1977; Wong and Brace, 1979]. This dilatation leads to a closure of pores and pre-existing cracks [Bachrach et al., 2000] which in turn leads to an elastic wave velocity and thermal conductivity increases. 

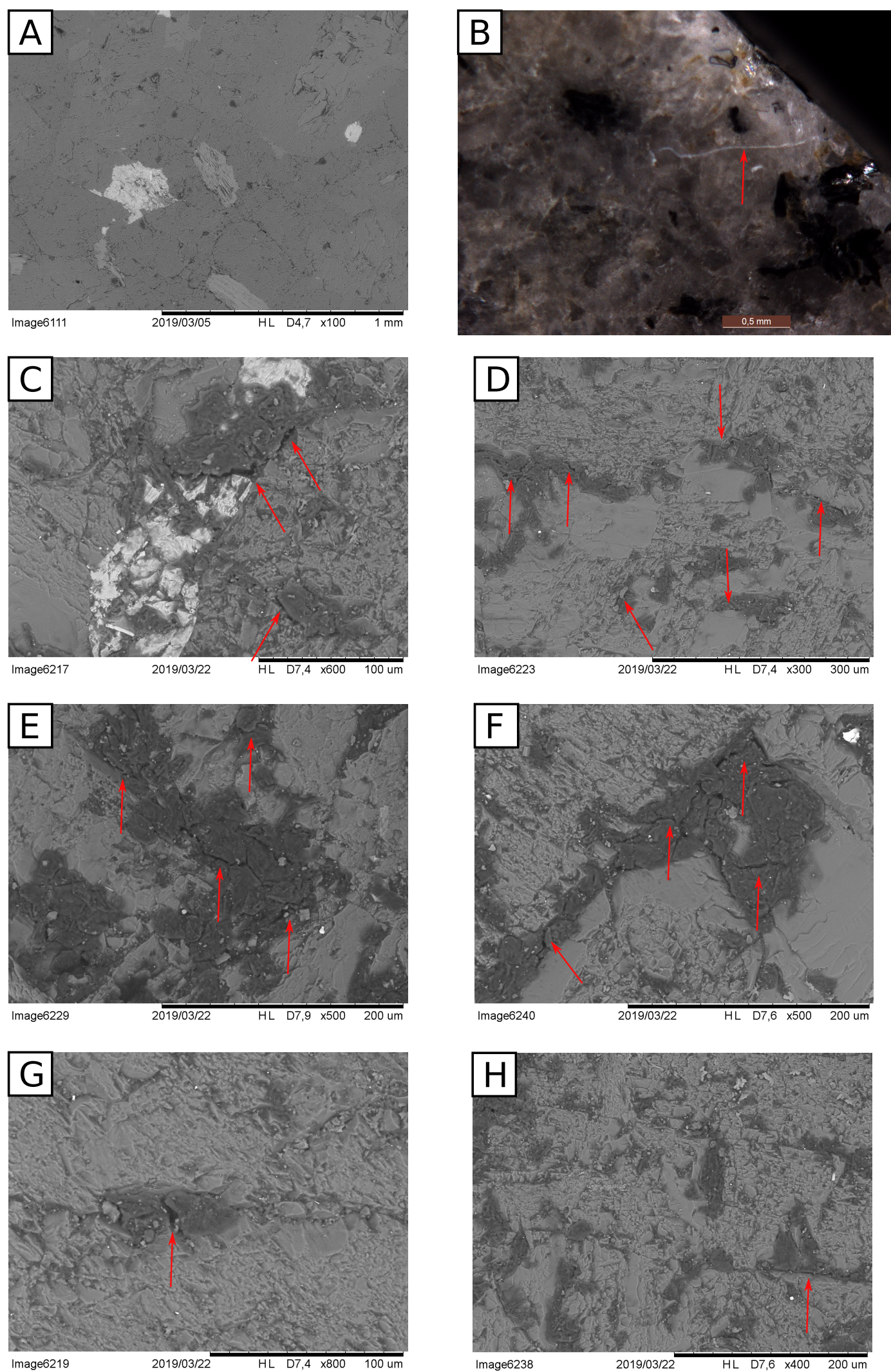

Figure 8 Microstructural observations in our cracked samples. a) Initial state with well closed joins. b) - f) Observations made on samples after the thermal shock protocols: b) from optical microscope, on the sample boundary and c) - f) from SEM. g) - h) Observations made on samples after the progressive cooling protocols with SEM. 
Then, according to Lin [2002], the crack initiation thermal threshold in granite is around $100-125^{\circ} \mathrm{C}$. However, as said before, a lower threshold can be found in literature (around $75^{\circ} \mathrm{C}$ according to Richter and Simmons [1974]). This threshold could be the competing process forcing the elastic wave velocity and thermal conductivity to decrease.

\subsection{Reproducibility of the thermal treatments}

When submitted to progressive cooling, the discrepancy between samples is about $\pm 100 \mathrm{~m} / \mathrm{s}$ and stays constant when damage increases from $100^{\circ} \mathrm{C}$ (Figure 4). When submitted to thermal shock, this discrepancy is much more significant and becomes even worsen when damage increases. Indeed the disparity between samples increases from $\pm 150 \mathrm{~m} / \mathrm{s}$ at $100^{\circ} \mathrm{C}$ to $\pm 350 \mathrm{~m} / \mathrm{s}$ at $180^{\circ} \mathrm{C}$. This difference between the two protocols is also observed with thermal conductivity, although less clearly: for the progressive cooling, a maximal disparity of $\pm 0.05 \mathrm{~W} / \mathrm{m} . \mathrm{K}$ is measured at $150^{\circ} \mathrm{C}$, while it is of $0.8 \mathrm{~W} / \mathrm{m} . \mathrm{K}$ for the thermal shock (at $180^{\circ} \mathrm{C}$ ).

Trying to summarize these data, we can say that thermal shock induces more substantial cracking than those generated by progressive cooling. However, this cracking is also less controlled and homogeneity between each sample is not reached, at least, in terms of elastic wave velocity and thermal conductivity variations.

This issue is quite problematic. Indeed, there are many studies which use slow heating and cooling [Wang et al., 2013] or thermal shock [Ougier-Simonin et al., 2011; Mallet et al., 2015] to control the extent of microcracking, in the aim of studying the influence of microcracks on rock properties. Though these thermal treatments are often performed at higher temperature from $200^{\circ} \mathrm{C}$ to $600^{\circ} \mathrm{C}$ [Zhao et al., 2017; Rong et al., 2018; Gautam et al., 2018], and data between studies are generally consistent. It could indicate that when the induced damage is more important, such as for a higher temperature, the issue of the reproducible aspect is non-existent and samples are similar to one another. Thus, when damage is present but no too significant, such as what we obtain in this study for low temperature, the reproducibility is challenging.

Perhaps, when thermally induced cracks are more significant, with higher temperature, this issue is over-passed. This interesting question should be the target of future contributions studying the reproducibility of thermally induced cracks considering a larger temperature range. Furthermore, various materials should be studied to discuss the reproducible aspect depending on initial porosity, matrix structure and pre-existing cracks, among other.

\subsection{Persistence of the low thermally induced cracks - after the progressive cooling}

After the progressive cooling, damage have been generated as it has been highlighted by elastic wave velocity and thermal conductivity decreases. It has been interpreted in terms of cracking and observed by SEM. Yet, sample's properties return to their initial state after almost 15 days, indicating a time-dependent crack closure. Successively, P-wave velocity then porosity and finally thermal conductivity return to their initial values. We would like here, to discuss a possible interpretation.

P-wave sensors have a central frequency of $1 \mathrm{MHz}$ thus a wavelength of $4 \mathrm{~mm}$. Therefore, they are mostly sensitive to cracks of $0.1 \mathrm{~mm}$-size while $\mathrm{Hg}$-porosity is sensitive to all cracks and pore. Thermal conductivity is sensitive to surface cracks, as spalling [Al-Omari et al., 2016], especially in our case considering the hot-wire apparatus.

Looking at the time evolution of these three parameters, we propose the following mechanism: at the beginning, and because of pressure equilibrium starting at the sample core, inner cracks started to close. It leads to a P-wave velocity and porosity re-increase. Progressively, all cracks, up to those of the surface will close. But because of the use of coupling gel, P-wave are not sensitive to the surface spalling and thus, they return to their initial state before the spalling cracks are closed and while the porosity and thermal conductivity are not yet returned to their initial states.

The time-dependent behavior of cracks due to a constant pressure has been discussed in literature [Mallet et al., 2015; Laubach et al., 2019]. It has been demonstrated that even under a critical stress threshold, crack length can be thermally controlled [Johnson and Paris , 1968; Lawn and Wilshaw, 1975]. They can propagate controlled by the stress intensity factor, $K_{I}$, or heal depending on the delta of activation energy $E_{a}-\delta E_{a}$ or $E_{a}+\delta E_{a}$ [Darot and Gueguen, 1986]. This notion is coming from the fact that there is an energy barrier between the two positions $x$ and $x \pm d x$ for a crack elementary propagation or closure. This energy barrier is linked to the crack propagation rate, $d l / d t$ and can be obtained with microscopic consideration thanks to Arhenius's law. A more explicit formulation can be found in Darot and Gueguen [1986]:

$$
\frac{d l^{+}}{d t}=i_{0} e^{\frac{-\left(E_{a}-\delta E_{a}\right)}{k T}} \quad \frac{d l^{-}}{d t}=i_{0} e^{\frac{-\left(E_{a}+\delta E_{a}\right)}{k T}},
$$

where $d l / d t$ is the crack length velocity, $E_{a}$ is the activation energy and $\delta E_{a}$ is the added energy to overpass the threshold of crack closure (left) or propagation (right). In most of the case, involved stresses tend to propagate the cracks and the second equation is predominant [Mallet et al., 2015]. This is the case for sub-critical crack propagation which is well studied in creep conditions for long-term behaviors. However, in our case the reduction of thermal stresses could lead to a predominant left equation leading to an exponential time-dependent crack closure.

To go further, the left equation can be developed into:

$$
\frac{d l}{d t}=i_{0} e^{\left(\frac{-E_{a}}{k T}\right)} e^{\left[-\frac{s}{k T}\left(\frac{K_{I}^{2}}{E_{0}}\right)\right]} .
$$


This development results from the definition of $\delta E_{a}$ [Darot and Gueguen, 1986], where the supplementary energy depends on temperature, $T$, the elementary step of crack closure $s$ and the Young modulus of the background, $E_{0}$.

When looking at Figure 7a, P-wave velocities (having the same behavior as crack density and so crack length) return to their initial state with a law that could be described by an exponential, with a correlation coefficient of 0.96. However, due to an important number of parameter to invert we cannot go further in these parameters identifications. Independent measurement should be performed to describe this law.

\section{Conclusion}

Two thermal treatments at low temperatures (up to $180^{\circ} \mathrm{C}$ ) have been performed on granite samples. A progressive and a shock one. Damage has been monitored during the successive treatments and for 15 days afterward by P-wave velocity and thermal conductivity. Porosity has been added for the time follow-up. Furthermore, after the thermal treatments, microscopic observations have been done thanks to SEM and optical microscope.

From our results, we observe that:

1. Thermal shock induces a significant damage even so considered temperatures are low. It is characterized by cracks developing inside and around grains (intergranular and intragranular cracks), at the surface and inside the sample. This protocol seems to be efficient in generating cracks. Nevertheless, there is large discrepancy between samples and reproducibility of this protocol is not certain at this level of temperature.

2. Progressive cooling brings a lower damage as observed by SEM. Indeed, diffuse cracks in the matrix have been noted. Furthermore, this damage is reproducible from one sample to another.

3. For the progressive cooling, a non-intuitive behavior has been observed around $150^{\circ} \mathrm{C}$ : the velocity and thermal conductivity slightly re-increase. It is interpreted in terms of a competing behavior between grain dilatation that tends to close the pre-existing cracks and the pores, and the development of new cracks.

4. With time, the samples damaged by progressive cooling return to their initial state. It seems that it follows a time-dependent exponential law that could explain the process of stress equilibrium with time.

5. Our multi-geophysical approach allows to highlight different crack behaviors. It shows the interest of considering various measurements to go further into possible crack interpretations.

Acknowledgements Data reported in this work can be obtained from the corresponding author (Céline Mallet) upon request. Financial support from Lamé Laboratory is gratefully acknowledged by the authors.

\section{References}

Al-Omari A, Brunetaud X, Beck K, Al-Mukhtar M (2016) Hygrothermal stress and damage risk in the stones of the castle of chambord-france. International Journal of Civil and Structural Engineering 4(3):doi:10.6088/ijcser.201304010039 (Cited page 11)

Bachrach R, Dvorkin J, Nur AM (2000) Seismic velocities and poisson's ratio of shallow unconsolidated sandsseismic properties of shallow sands. Geophysics 65(2):559-564 (Cited page 9)

Bauer S, Johnson B, et al. (1979) Effects of slow uniform heating on the physical properties of the westerly and charcoal granites. In: 20th US symposium on rock mechanics (USRMS), American Rock Mechanics Association (Cited page 9)

Beck K, Janvier-Badosa S, Brunetaud X, Torok A, Al-Mukhtar M (2016) Non-destructive diagnosis by colorimetry of building stone subjected to high temperatures. European Journal of Environmental and Civil Engineering 20(6):643-655 (Cited page 1)

Belayachi N, Mallet C, El Marzak M (2019) Thermally-induced cracks and their effects on natural and industrial geomaterials. Journal of Building Engineering 25:100806 (Cited pages 1 and 9)

Birch F (1960) The velocity of compressional waves in rocks to 10 kilobars, part 1. Journal of Applied Mechanics 65:1083-1102 (Cited page 3)

Cappa F, Rutqvist J (2011) Modeling of coupled deformation and permeability evolution during fault reactivation induced by deep underground injection of co2. International Journal of Greenhouse Gas Control 5(2):336-346 (Cited page 1)

Carcione JM, Ursin B, Nordskag JI (2007) Cross-property relations between electrical conductivity and the seismic velocity of rocks. Geophysics 72(5):E193-E204 (Cited page 4)

Caspari E, Milani M, Rubino JG, Muller TM, Quintal B, Holliger K (2016) Numerical upscaling of frequency-dependent p-and s-wave moduli in fractured porous media. Geophysical Prospecting 64(4):1166-1179 (Not cited)

Chaki S, Takarli M, Agbodjan W (2008) Influence of thermal damage on physical properties of a granite rock: porosity, permeability and ultrasonic wave evolutions. Construction and Building Materials 22(7):1456-1461 (Cited pages 1, 7, and 9)

Chen S, Yang C, Wang G (2017) Evolution of thermal damage and permeability of beishan granite. Applied Thermal Engineering 110:1533-1542 (Cited page 1)

Cooper H, Simmons G (1977) The effect of cracks on the thermal expansion of rocks. Earth and Planetary Science Letters 36:404-412 (Cited page 9)

Darot M, Gueguen Y (1986) Slow crack growth in minerals and rocks: Theory and experiments. Pure and Applied Geophysics 124(4):677-692 (Cited page 11)

Darot M, Gueguen Y, Baratin M (1992) Permeability of thermally cracked granite. Geophysical Research Letter 19(9):869-872 (Cited page 9)

David C, Menéndez B, Darot M (1999) Influence of stress-induced and thermal cracking on physical properties and microstructure of la peyratte granite. International Journal of Rock Mechanics and Mining Sciences 36(4):433-448 (Cited pages 1, 7, and 9)

Dwivedi R, Goel R, Prasad V, Sinha A (2008) Thermo-mechanical properties of indian and other granites. International Journal of Rock mechanics and mining Sciences 45(3):303-315 (Cited page 1)

Feng Z, Zhao Y, Zhou A, Zhang N (2012) Development program of hot dry rock geothermal resource in the yangbajing basin of china. Renewable energy 39(1):490-495 (Cited page 1)

Fredrich JT, Wong Tf (1986) Micromechanics of thermally induced cracking in three crustal rocks. Journal of Geophysical Research: Solid Earth 91(B12):12743-12764 (Cited pages 7 and 9) 
Friedman M, Johnson B, et al. (1978) Thermal cracks in unconfined sioux quartzite. In: 19th US Symposium on Rock Mechanics (USRMS), American Rock Mechanics Association (Cited page 9)

Gautam P, Verma A, Jha M, Sharma P, Singh T (2018) Effect of high temperature on physical and mechanical properties of jalore granite. Journal of Applied Geophysics 159:460-474 (Cited pages 1 and 11)

Glover P, Baud P, Darot M, Meredith P, Boon S, LeRavalec M, Zoussi S, Reuschlé T (1995) $\alpha / \beta$ phase transition in quartz monitored using acoustic emissions. Geophysical Journal International 120(3):775-782 (Cited pages 7 and 9)

Griffiths L, Heap M, Baud P, Schmittbuhl J (2017) Quantification of microcrack characteristics and implications for stiffness and strength of granite. International Journal of Rock Mechanics and Mining Sciences 100:138-150 (Cited page 1)

Griffiths L, Lengliné O, Heap M, Baud P, Schmittbuhl J (2018) Thermal cracking in westerly granite monitored using direct wave velocity, coda wave interferometry, and acoustic emissions. Journal of Geophysical Research: Solid Earth 123(3):2246-2261 (Cited page 7)

Guéguen Y, Kachanov M (2011) Effective elastic properties of cracked rocks - an overview, in, mechanics of crustal rocks. CISM Courses and Lectures 533:73-125 (Cited pages 1 and 3)

Hadley K (1976) Comparison of calculated and observed crack densities and seismic velocities in westerly granite. Journal of Geophysical Research 81(20):3484-3494 (Cited page 1)

Han T, Best AI, Sothcott J, North LJ, MacGregor LM (2015) Relationships among low frequency (2 hz) electrical resistivity, porosity, clay content and permeability in reservoir sandstones. Journal of Applied Geophysics 112:279-289 (Cited page 4)

Jansen D, Carlson S, Young R, Hutchins D (1993) Ultrasonic imaging and acoustic emission monitoring of thermally induced microcracks in lac du bonnet granite. Journal of Geophysical Research: Solid Earth 98(B12):22231-22243 (Cited page 9)

Jin P, Hu Y, Shao J, Zhao G, Zhu X, Li C (2019) Influence of different thermal cycling treatments on the physical, mechanical and transport properties of granite. Geothermics 78:118-128 (Cited pages 1, 7, and 9)

Johnson B, Gangi A, Handin J (1978) Thermal cracking of rock subjected to slow, uniform temperature changes. In: 19th US Symposium on Rock Mechanics (USRMS), American Rock Mechanics Association (Cited page 7)

Johnson HH, Paris PC (1968) Sub-critical flaw growth. Engineering Fracture Mechanics 1(1):3-45 (Cited page 11)

Jones G, Zielinski M, Sentenac P (2012) Mapping desiccation fissures using 3-d electrical resistivity tomography. Journal of Applied Geophysics 84:39-51 (Cited page 4)

Kachanov M (1980) Continuum model of medium with cracks. Journal of the engineering mechanics division 106:1039-1051 (Cited page 3)

Kant MA, Meier T, Rossi E, Schuler M, Becker D, Höser D, Rudolf von Rohr P (2017) Thermal spallation drilling-an alternative drilling technology for hard rock drilling. Oil Gas 3(1):OG23-OG25 (Cited page 1)

Kemna A, Vanderborght J, Kulessa B, Vereecken H (2002) Imaging and characterisation of subsurface solute transport using electrical resistivity tomography (ert) and equivalent transport models. Journal of Hydrology 267(3-4):125-146 (Cited page 4)

Kim K, Kemeny J, Nickerson M (2014) Effect of rapid thermal cooling on mechanical rock properties. Rock mechanics and rock engineering 47(6):20052019 (Cited page 1)

Kranz RL (1983) Microcracks in rocks: a review. Tectonophysics 100(1-3):449-480 (Cited page 1)

Kumari W, Ranjith P, Perera M, Chen B, Abdulagatov I (2017) Temperature-dependent mechanical behaviour of australian strathbogie granite with different cooling treatments. Engineering geology 229:31-44 (Cited page 1)

Laubach SE, Lander RH, Criscenti LJ, Anovitz LM, Urai JL, Pollyea RM, Hooker JN, Narr W, Evans MA, Kerisit SN (2017) The Role of Chemistry in Fracture Pattern Development and Opportunities to Advance Interpretations of Geological Materials. Reviews of Geophysics 57 doi:10.1029/2019RG000671 (Cited page 11)

Lawn B, Wilshaw R (1975) Fracture of brittle solids. Cambridge university press (Cited page 11)

Lin W (2002) Permanent strain of thermal expansion and thermally induced microcracking in inada granite. Journal of Geophysical Research: Solid Earth 107(B10):ECV-3 (Cited pages 1, 2, 7, and 9)

Mallet C, Fortin J, Guéguen Y, Bouyer F (2013) Effective elastic properties of cracked solids: an experimental investigation. International Journal of Fracture 182(2):doi: 10.1007/s10704-013-9855-y (Cited page 2)

Mallet C, Fortin J, Guéguen Y, Bouyer F (2015) Brittle creep and subcritical crack propagation in glass submitted to triaxial conditions. Journal of Geophysical Research 120(2):879-893, doi: 10.1002/2014JB011231 (Cited pages 1 and 11)

Nakaten N, Schlüter R, Azzam R, Kempka T (2014) Development of a techno-economic model for dynamic calculation of cost of electricity, energy demand and co2 emissions of an integrated ucg-ccs process. Energy 66:779-790 (Cited page 1)

Nasseri M, Schubnel A, Young R (2007) Coupled evolutions of fracture toughness and elastic wave velocities at high crack density in thermally treated westerly granite. International Journal of Rock Mechanics and Mining Sciences 44(4):601-616 (Cited page 1)

Nasseri M, Schubnel A, Benson PM, Young R (2009) Common evolution of mechanical and transport properties in thermally cracked westerly granite at elevated hydrostatic pressure. Rock Physics and Natural Hazards 166:5-7 (Cited page 9)

Ndao B, Do DP, Hoxha D (2017) P and s wave anisotropy to characterize and quantify damage in media: laboratory experiment using synthetic sample with aligned microcracks. Geophysical Prospecting 65:181-200 (Cited page 3)

Ougier-Simonin A, Guéguen Y, Fortin J, Schubnel A, Bouyer F (2011) Permeability and elastic properties of cracked glass under pressure. Journal of Geophysical Research 116:B07203, doi:10.1029/2010JB008077 (Cited pages 2, 9, and 11)

Richter D, Simmons G (1974) Thermal expansion behavior of igneous rocks. In: International Journal of Rock Mechanics and Mining Sciences \& Geomechanics Abstracts, Elsevier, vol 11, pp 403-411 (Cited pages 1, 7, and 9)

Ringwood A (1985) Disposal of high-level nuclear wastes: a geological perspective. Mineralogical magazine 49(351):159-176 (Cited page 1)

Rong G, Peng J, Cai M, Yao M, Zhou C, Sha S (2018) Experimental investigation of thermal cycling effect on physical and mechanical properties of bedrocks in geothermal fields. Applied Thermal Engineering 141:174-185 (Cited pages 1 and 11)

Rummel F (1992) Physical properties of the rock in the granitic section of borehole gpk1, soultz-sous-forêts. Geothermal Energy in Europe: the soultz hot dry rock project pp 199-216 (Cited page 1)

Siratovich PA, Villeneuve MC, Cole JW, Kennedy BM, Bégué F (2015) Saturated heating and quenching of three crustal rocks and implications for thermal stimulation of permeability in geothermal reservoirs. International Journal of Rock Mechanics and Mining Sciences 80:265-280 (Cited pages 2 and 9)

Sarout J (2006) Propriétés physiques et anisotropie des roches argileuses: Modélisation micromécanique et expériences triaxiales. PhD thesis (Not cited)

Spray J (2010) Frictional melting processes in planetary materials: From hypervelocity impact to earthquakes. Annual Review of Earth and Planetary Sciences 38:221-254 (Cited page 2)

Storz H, Storz W, Jacobs F (2000) Electrical resistivity tomography to investigate geological structures of the earth's upper crust. Geophysical Prospecting 48(3):455-471 (Cited page 4)

Walsh J (1965) The effect of cracks on the uniaxial elastic compression of rocks. Journal of Geophysical Research 70(2):399-411 (Cited page 3)

Wang X, Schubnel A, Fortin J, Gueguen Y, Ge HK (2012) High Vp/Vs ratio: Saturated cracks or anisotropy effects? Geophysical Research Letters 39:L11307, doi:10.1029/2012GL051742 (Cited page 2) 
Wang X, Schubnel A, Fortin J, Gueguen Y, Ge HK (2013) Physical properties and brittle strength of thermally cracked granite under confinement. Journal of Geophysical Research 118:6099-6112, doi: 10.1002/2013JB010340 (Cited pages 1, 2, and 11)

Wong T, Brace W (1979) Thermal expansion of rocks: Some measurements at high pressure. Tectonophysics 57:95-117 (Cited page 9)

Wuttke F, Sattari A, Rizvi Z, Motra H (2017) Advanced meso-scale modelling to study the effective thermo-mechanical parameter in solid geomaterial. In: Advances in Laboratory Testing and Modelling of Soils and Shales, Springer, pp 85-95 (Cited page 2)

Xiong MX, Liew JR (2016) Mechanical behaviour of ultra-high strength concrete at elevated temperatures and fire resistance of ultra-high strength concrete filled steel tubes. Materials \& Design 104:414-427 (Cited pages 1 and 4)

Yong C, Wang Cy (1980) Thermally induced acoustic emission in westerly granite. Geophysical Research Letters 7(12):1089-1092 (Cited page 7)

Zhang F, Zhao J, Hu D, Skoczylas F, Shao J (2018) Laboratory investigation on physical and mechanical properties of granite after heating and water-cooling treatment. Rock Mechanics and Rock Engineering 51(3):677-694 (Cited pages 1, 2, and 9)

Zhao X, Zhao Z, Guo Z, Cai M, Li X, Li P, Chen L, Wang J (2018) Influence of thermal treatment on the thermal conductivity of beishan granite. Rock Mechanics and Rock Engineering 51(7):2055-2074 (Cited page 1)

Zhao Y, Feng Z, Zhao Y, Wan Z (2017) Experimental investigation on thermal cracking, permeability under hthp and application for geothermal mining of hdr. Energy 132:305-314 (Cited pages 1 and 11) 